\title{
Guidelines
}

Skin

Appendage

Disorders

\section{Trichologist, Dermatotrichologist, or Trichiatrist? A Global Perspective on a Strictly Medical Discipline}

\author{
Ralph Michel Trüeb ${ }^{a}$ Sergio Vañó-Galván ${ }^{b}$ Daisy Koperac Vicky M.L. Jolliffe ${ }^{d}$ \\ Demetrios loannides ${ }^{e}$ Maria Fernanda Reis Gavazzoni Dias ${ }^{f}$ \\ Melanie Macpherson ${ }^{g}$ Javier Ruíz Ávila ${ }^{\text {h }}$ Aida Gadzhigoroeva ${ }^{i}$ \\ Julya Ovcharenko ${ }^{j}$ Won-Soo Lee ${ }^{k}$ Sundaram Murugusundram ${ }^{\prime}$ \\ Sotaro Kurata $^{\mathrm{m}}$ Mimi Chang ${ }^{\mathrm{n}}$ Chuchai Tanglertsampan ${ }^{\circ}$ \\ ${ }^{a}$ Center for Dermatology and Hair Diseases Professor Trüeb and University of Zurich, Zurich, Switzerland; ${ }^{\mathrm{b}}$ Ramon \\ y Cajal Hospital, University of Alcala, Madrid, Spain; ' ${ }^{C}$ Center of Aesthetic Medicine, Department of Dermatology, \\ Medical University Graz, Graz, Austria; ${ }^{\mathrm{d}}$ The Royal London Hospital, London, UK; ${ }^{\mathrm{e}} 1$ st Department of Dermatology- \\ Venereology, Hospital of Skin and Venereal Diseases, Aristotle University Medical School, Thessaloniki, Greece; \\ ${ }^{f}$ Department of Dermatology, Centro de Ciências Médicas, Hospital Universitário Antonia Pedro, Universidade \\ Federal Fluminense, Niterói, Brazil; 9 Department of Dermatology and Venereology, San Gabriel Clinic, Lima, Peru; \\ ${ }^{h}$ Dermedica Clinic, Polanco, Mexico City, Mexico; ' Moscow Scientific and Practical Center of Dermatology and \\ Cosmetology, Moscow City Health Department, Moscow, Russia; 'jGeneral and Clinical Immunology and Allergology \\ Department, School of Medicine, V.N. Karazin Kharkiv National University, Kharkiv, Ukraine; ${ }^{k}$ Department of \\ Dermatology, Wonju College of Medicine, Yonsei University, Gangwon-do, Republic of Korea; 'Chennai Skin \\ Foundation and Yesudian Research Institute, Chennai, India; ${ }^{m}$ Beppu Garden Hill Clinic and Kurata Clinic, Beppu, \\ Japan; ${ }^{n}$ Prince of Wales Hospital and the Chinese University of Hong Kong, Hong Kong, China; ${ }^{\circ}$ Department of \\ Dermatology, Bumrungrad International Hospital, Mae Fah Luang University Hospital, Bangkok, Thailand
}

\section{Keywords}

Hair restoration - Evidence-based medicine - Trichologist ·

Dermatotrichologist · Trichiatrist

\begin{abstract}
Few dermatologic problems carry as much emotional overtones as the complaint of hair loss. The best way to alleviate the distress related to hair loss is to effectively treat it. In fact, one of the oldest medical professions is the Egyptian physician who specialized on diseases of the head. And yet, from
\end{abstract}

ancient Egypt down to modern times, human hair has been the object of superstition and mystery. Remarkably and despite the genuine advances in effective medical treatments, hair cosmetics, and surgical procedures, phony hair loss solutions continue to be marketed with an amazing success. In 1860, a quasi-scientific interest in hair loss and hair care originated in a London barbershop and became known as trichology, with the Institute of Trichologists being founded. Other corporations successively followed internationally, but it was only in 2010 that the term dermatotrichologist was proposed for board-certified dermatologists dealing with the scientific study of the hair and scalp, in contrast to the

\section{KARGER}

(c) 2018 S. Karger AG, Basel

E-Mail karger@karger.com

www.karger.com/sad
Ralph M. Trüeb

Center for Dermatology and Hair Diseases Professor Trüeb

Bahnhofplatz 1A, CH-8304 Wallisellen (Switzerland)

E-Mail r.trueeb@ derma-haarcenter.ch 
trichologist who is rather associated with laity and cosmetics than with medical professionalism, or - worse - offers opportunities to possible imposters with a primary commercial interest. The new term "trichiatrist" is proposed, literally meaning the "medical treatment of the hair," to designate the strictly medical professional dealing with the hair and scalp in health and disease. Trichiatrists differ from trichologists by virtue of being physicians. The quality and stringency of their graduate medical training is identical to that of other physicians.

(c) 2018 S. Karger AG, Base

The medical practice is divided among them (the Egyptians) as follows: each physician is for one kind of sickness, and no more, and all places are crowded with physicians: for there are physicians for the eyes, physicians for the head, physicians for the teeth, physicians for the stomach, and for internal disease.

Herodotus, Histories 2,84

Few dermatologic problems carry as much emotional overtones as the complaint of hair loss, and the best way of alleviating the distress related to hair loss is to treat it effectively. In fact, one of the oldest medical professions documented in Greek historian and traveler Herodotus' "Histories" is the Egyptian physician who specialized on diseases of the head. Herodotus (484-425 BC) was the first historian known to have broken from the Homeric tradition to treat historical subjects as a method of investigation by collecting his materials systematically and critically and arranging them into a historiographic narrative. Thereby, Herodotus provides us with much information about the nature of the world and the status of science during his lifetime [1].

The most remote representations of hair loss that can be traced back around 30'000 years to wall engravings in a prehistorical cave are somewhat reminiscent of today's categorization of pattern hair loss, and the story is still ongoing in our modern society [2]. The first written document on the importance of making a distinction between inflammatory alopecia (tzaraat, Hebrew צרעת, breaking out on the head) from common baldness dates back to the Old Testament. The term tzaraat describes disfigurative conditions of the skin, hair of the beard and head. All variations are mainly referred to in chapters 1314 of Leviticus (written ca. 538-332 BC) [3].

And yet, from the 4'000-year-old medical papyri of the ancient Egyptians down to modern times, human hair growth and color have been the object of superstition and mystery, besides arousing cosmetic and medical interest [4]. For the prevention or treatment of hair loss, countless

Trichologist, Dermatotrichologist, or Trichiatrist? herbal solutions, oils, lotions, magic pills, and even spiritual invocations have been advocated. What is remarkable about the history of hair loss cures is that despite the more recent genuine advances in effective medical treatments, hair cosmetics, and surgical procedures, phony hair loss solutions continue to be marketed today with an amazing success. Despite their outrageous claims, most lack scientifically measurable efficacy in preventing hair loss or promoting hair growth. As much today as in biblical times, people are so desperately concerned about their hair loss that they want to believe some miracle cure or some charismatic healer will help them.

The first genuine scientific studies on hair probably began when the English natural philosopher and polymath Robert Hooke (1635-1703) studied the hair shaft under the microscope [5] and the Italian biologist and physician Marcello Malphighi (1628-1694) described the anatomy of the hair follicle in his treatise "De pilis observationes" [6]. However, the biology of hair growth was not understood at this time. In search of information before engaging in the development of a new hair growthpromoting agent, makers of cosmetics turned to the medical faculty and received only very vague indications. When questioned, doctors remained evasive, and the hair was thus abated to malpractices of all sorts. The charlatan chemists of this age were as ineffectual but significantly more risky than their physician colleagues. With certain lotions in which toxic ingredients playing a role, accidents must have occurred frequently, and the French chemist Antoine Laurent de Lavoisier (1743-1794) urged for regulatory control of ingredients, which was never realized. France held the monopoly for miraculous elixirs and exported to America its "Eau de Ninon de L'enclos," named after a beautiful courtesan whom had preserved her hair to the age of 85 years [7]. The French physician Auguste Caron, who published an "Encyclopedia of Beauty" [8] in 1806, warned the women of fashion of his time against the potential toxicity of products of mysterious origin, as a wretched woman had been driven to madness after using a tonic called "Eau de Chine." The products remained just as dubious, whilst acquiring sentimental names as befitting the Romantic period. With the advance of medical technologies, ultraviolet light-emitting lamps, electrical scalp stimulators, and vacuum-cap machines have joined the repertory of treatments alleged to help stimulating the follicles to grow hair.

Probably the first sound scientific attempt toward hair restoration was the demonstration that it was possible to transplant hair from a hair-bearing to a non-hair bearing area in 1822 by the German medical student Johann Dief- 
fenbach (1792-1847) [9]. However, it was not until 1939 that the era of hair transplantation began in earnest with the efforts of the Japanese physician Shoji Okuda (18861962) and later the New York dermatologist Norman Orentreich. Today, we hardly know anything about the medical background of Shoji Okuda, and his seminal work on hair transplantation remained virtually unknown outside Japan because of the outbreak of World War II. Moreover, the papers were written using old kanji (Japanese pictographs) and are consequently unintelligible even to modern Japanese medical readers. It was only in 2004 that the "Okuda Papers" were translated into English by Yoshihiro Imagawa, a retired gynecologist trained in the USA [10]. Okuda developed a circular scalpel for the purpose of transplanting hair into areas of alopecia [11]. In 1959, Norman Orentreich established the pivotal theory of donor dominance of the hair transplant. The basis of the theory was that plugs of hair follicles taken from the occipital scalp would continue growing when moved to the balding frontal scalp because those hair follicles were genetically programmed to do so. The concept became the foundation for the entire ensuing field of hair restoration surgery, and for the following decades, dedicated surgeons all over the globe have worked on refining the method with today close to natural results [12].

In 1860, a quasi-scientific interest in hair loss and hair care originated in a London barbershop under a self-styled Professor Wheeler. By1902, this interest in hair disorders became known as trichology, and the first Institute of Trichologists was founded. The International Association of Trichologists (IAT) was established in California in 1974 and offers a course by home-study for the training of students internationally who desire more knowledge about hair. Registered members can use the letters IAT after their name. Other corporations that have evolved globally are the Australian Institute of Trichology, the US Trichology Institute, the Argentine Association of Trichology (AATRI), and the World Trichology Society. Trichologists themselves are not normally medically qualified, although members of the medical profession can undertake courses and/or careers within trichology. Trichologists are not medically qualified but are taught the practice of care and treatment of the human hair and scalp in health and disease within their restricted but specialized role [13]. Nevertheless, there has been criticism regarding the ability of the public to reliably differentiate nonmedical trichologists from unqualified charlatans who monopolize publicity and proliferate in the high street, and concerns have been voiced about how to educate the public in choosing appropriate practitioners $[14,15]$.
The dawn of the modern age of pharmacological therapy of hair loss can be traced back to the original clinical studies performed with topical minoxidil in the 1980s [16] and with oral finasteride in the 1990s [17]. For the first time in 4'000 years of history, pharmacological agents have been scientifically proven to stop hair loss and to promote hair growth. It is the introduction of these drugs into the treatment of hair loss that has heralded the emancipation of the treatment of hair loss from its age-old tradition of quackery. With respect to the study design and criteria for efficacy and safety, the respective clinical studies have set the standards for any agent with the claim of promoting hair growth.

Although testing medical interventions for efficacy had existed since the time of Avicenna's (980-1037) “The Canon of Medicine" in the 11th century [18], it was only in the 20th century that this effort evolved to impact almost all fields of health care and policy. In 1967, the American physician and mathematician Alvan R. Feinstein (1925-2001) published his seminal work "Clinical Judgment" [19], which together with Archie Cochrane's (1909-1988) celebrated book "Effectiveness and Efficiency" [20] led to an increasing acceptance of clinical epidemiology and controlled studies during the 1970s and 1980 s and prepared the way for the institutional development of evidence-based medicine (EBM) in the 1990s. Ultimately, EBM aims for the ideal that healthcare professionals should make conscientious, explicit, and judicious use of the best available evidence gained from the scientific method to clinical decision making. It seeks to assess the strength of the evidence of risks and benefits of diagnostic tests and treatments, using techniques from science, engineering, and statistics, such as the systematic review of medical literature, meta-analysis, risk-benefit analysis, and randomized controlled trials.

Nonetheless, the limited success rate of evidence based therapies points to a more important complexity of hair loss and its management. Ultimately, EBM guidelines do not remove the problem of extrapolation to different populations. Even if several top-quality studies are available, questions remain as to how far and to which populations their results may be generalized. Certain groups have been historically under-researched, such as special age groups, ethnic minorities, and people with comorbid conditions. EBM applies to groups of people, but this should not preclude clinicians from using their personal experience in deciding how to treat the individual patient at hand.

For centuries, physicians propagated the viability of a complex approach in the diagnosis and treatment of dis- 
ease, while modern medicine, which boasts a wide range of diagnostic methods and variety of therapeutic procedures, stresses specification. This raises the question: How does one wholly evaluate the state of a patient who suffers from a number of diseases simultaneously, where to start from and which disease(s) require(s) primary and subsequent treatment? This crucial question remained unanswered until 1970 when Alvan R. Feinstein coined the term "comorbidity" [21], which has been defined as "presence of one or more additional diseases co-occurring with a primary disease; or the effect of such additional diseases, whereby the additional disorder may also be a behavioural or mental disorder." The effect of comorbid pathologies on clinical implications, diagnosis, prognosis, and therapy of trichologic conditions is polyhedral and patient specific. Therefore, presence of comorbidity must be taken into account when selecting the algorithm of the diagnosis and treatment plan for any given condition, including trichologic disease [22].

Ultimately, the dermatologist participates with the other medical disciplines in the diagnosis and treatment of all types of hair problems as they may relate to systemic disease [23].

On the other hand, hair loss is an important cause of discomfort and disability. The general physician is not always aware of the significance of hair loss and therefore may fail to refer patients with hair disorders to the dermatologist for appropriate management. Too often a delay in correct diagnosis and the resultant delay in initiation of appropriate therapy results in potentially irreversible loss of hair, prolonged discomfort, and possible disfigurement.

As with any medical problem, the patient complaining of hair loss requires a comprehensive medical and drug history, physical examination of the hair and scalp, and appropriate laboratory evaluation to identify the cause. Dermatologic conditions are satisfying to diagnose as most conditions are visibly present at the time of consultation. Just looking would seem to be the simplest of diagnostic skills, and yet its very simplicity can result in its being overlooked. To reach the level of true artistry, looking must be a skillful active undertaking. The skill comes in interpreting the visual signs and having made a diagnosis hunting for the cause. The diagnostic process may be one of instantaneous recognition. The informed look is the one most practiced by the knowledgeable dermatologist, and is a combination of understanding, experience, and visual memory. If a visual diagnosis is not possible, then diagnostic tests are needed in the forms of specific dermatological examination techniques such as dermoscopy and laboratory evaluation (trichogram, biochemical investigations, microbiological studies, or scalp biopsy) as needed.

A prerequisite for delivering appropriate patient care is an understanding of the underlying pathologic dynamics of hair loss and its potentially multitudinous causes. By approaching the hair loss patient in a methodical way, commencing with objects the simplest and easiest to recognize, and ascending step by step to understanding the more complex aspects, an individualized treatment plan can be designed. Once the diagnosis is established, appropriate treatment is likely to be successful.

Alongside progress in clinical diagnosis and care, advances in the understanding of hair growth biology and its pathologic conditions is being made at a high pace thanks to the impetus of a generation of both astute clinicians and basic scientists interested in the hair follicle, the sophistication of molecular biology, and new technologies. Across the globe, Hair Research Societies have evolved such as the Australasian Hair and Wool Research Society; the European Hair Research Society; the North American Hair Research Society; the Society of Hair Research, Japan; the Korean Hair Research Society; the Hair Research Society of India; the Association of Professional Society of Trichologists, Moscow, Russia; and the Ukrainian Hair Research Society. These communities of interest and of practice regularly meet to bring together enthusiastic hair biologists and dermatologists for the exchange and discussion of the advances in hair research and clinical practice in the fields of genetics, molecular biology, immunology, aging, neurobiology, psychosomatics, diagnostic techniques and technologies, pharmacology, hair transplantation surgery, stem cells, and tissue-engineering research [24].

It was with the backdrop that in 2010 Dr. Patrick Yesudian, dermatologist practicing in India and founder of the Hair Research Society of India, proposed the term "dermatotrichologist" for board-certified dermatologists dealing with the scientific study of the hair and scalp in health and disease to distinguish them from the trichologist, who is not medically qualified and more involved with the cosmetic aspects of hair, or - worse - could offer opportunities to imposters with a primary commercial interest [25]. At the 2012 meeting of the Hair Research Society of India in UNESCO world heritage site Mamallapuram, the theme of the meeting was "To Abolish Quackery in Trichology," and the consensus was that good medical practice in clinical trichology aims at (from [26]):

- Understanding the hair patient on an emotional level and the medical problem on a technical level 
- Delivering sound patient education and effective trichologic therapy

- Representing trichology as a discipline based on evidence from science, engineering, and statistics

- Setting standards of good medical practice in trichology

- Supporting progress in trichology through continuous medical education

- Abolishing quackery in trichology

The ultimate question that arises, however, is whether the term "trichiatrist" for board-certified health care professionals (MDs) dealing with hair may be the yet more appropriate designation than trichologist or dermatotrichologist, in analogy to the term psychiatrist versus psychologist.

The term psychiatrist was originally coined by the German physician Johann Christian Reil in 1808 [27] and literally means the "medical treatment of the soul" (psych - "soul," and -iatry - "medical treatment" from ancient Greek). Psychiatrists differ from psychologists in that they are physicians and have postgraduate training called residency in psychiatry (usually $4-5$ years). The quality and stringency of their graduate medical training is identical to that of all other medical disciplines. Psychiatrists can therefore counsel patients, prescribe medication, conduct physical examinations, and order laboratory tests.

Parallels may easily be drawn with the care of hair disorders, when the same concept applies to the trichiatrist versus the trichologist, literally meaning the "medical treatment of the hair" (trich - "hair" from ancient Greek) to designate the strictly medical professional dealing with the hair and scalp in health and disease, with the capacity to counsel patients, prescribe medication, conduct physical examinations, and order pertinent laboratory tests as needed.

Furthermore, psychiatrists, more than other physicians, specialize in the doctor-patient relationship and are trained in therapeutic communication techniques $[28,29]$.

In very much the same manner, prerequisites for a successful management of hair loss are twofold: on the technical and on the psychological level. On the technical level, prerequisites are a specific diagnosis, a profound understanding of the underlying pathophysiology, and the best available evidence gained from the scientific method for clinical decision making. On the psychological level, one must be sure that the patient's key concerns have been directly and specifically solicited and addressed: acknowledge the patient's perspective on the hair loss prob- lem, explore patient's expectations from treatment, and educate patients into the basics of the hair cycle, and why patience is required for effective cosmetic recovery. Physicians should recognize that alopecia goes well beyond the simple physical aspects of hair loss and acknowledge the psychological impact of hair loss.

Ultimately, successful communication is the main reason for patient satisfaction and treatment success, while failed communication is the main reason for patient dissatisfaction, irrespective of treatment success [30].

In summary, as a trichiatrist, communication skills and treatment success require a genuine interest in recognizing and treating hair loss with knowledgeability on the scientific level and a genuine interest in supporting the patient complaining of hair loss with compassion on the emotional and psychological level. Ideally, credentials should include:

- Medical degree and residency in a medical discipline relevant to the management of the hair and scalp in health and disease (usually dermatology)

- Certification of traineeship or fellowship in the scientific study of the hair and scalp in health and disease with a syllabus expressing accountability and commitment

- Membership in one of the Hair Research Societies or Societies of Hair Restoration Surgery with regular participation at respective scientific meetings

- Accredited CME in the respective professional activity Let's welcome the trichiatrist to the list of tricky "trichs" in dermatology [31]!

\section{Statement of Ethics}

The authors have no ethical conflicts to disclose.

\section{Disclosure Statement}

The authors have no conflicts of interest to disclose.

\section{References} medicine. Vesalius 2010;(suppl):3-5.

2 Van Neste D: Aging form Where to There?; in Trüeb RM, Tobin DJ (eds.): Aging Hair. Springer Berlin Heidelberg, 2010, pp. vii-viii (Foreword).

-3 Freilich AR: Tzaraat- "biblical leprosy". J Am Acad Dermatol 1982;6:131-134.

4 Trüeb RM; Swiss Trichology Study Group: The value of hair cosmetics and pharmaceuticals. Dermatology 2001;202:275-282. 
5 Lawson I: Crafting the microworld: how Robert Hooke constructed knowledge about small things. Notes Rec R Soc Lond 2016;70: 23-44.

-6 Campo D, D’Acunzo V: Doctors and baldness: a five thousand year old challenge. G Ital Dermatol Venereol 2016;151:93-101.

7 Duchêne, Roger, de l'Enclos N: La courtisane du grand siècle (Paris 1984).

8 Caron A: Toilette des dames, ou Encyclopédie de la beauté. Paris, A. G. Debray, 1806.

9 Dieffenbach JF: Nonnulla de regeneratione et transplantatione. Diss. inaug. Herbipolis, 1822 .

10 Jimenez F, Shiell RC: The Okuda papers: an extraordinary - but unfortunately unrecognized - piece of work that could have changed the history of hair transplantation. Exp Dermatol 2015;24:185-186.

-11 Inui S, Itami S: Dr Shoji Okuda (1886-1962): the great pioneer of punch graft hair transplantation. J Dermatol 2009;36:561-562.

12 Orentreich DS, Orentreich N: Hair transplantation. J Dermatol Surg Oncol 1985;11:319324.

13 Mason J: The role of the trichologist. Clin Exp Dermatol 2002;27:422-425.

-14 Mysore V, Khopkar U: Check if your trichologist is a doctor: need for educating the public. Indian J Dermatol Venereol Leprol 2007; 73:147-148.
15 Padmanabhan P: Ethics in trichology. Int J Trichology 2010;2:40-41.

16 Zins GR: The history of the development of minoxidil. Clin Dermatol 1988;6:132-147.

17 Libecco JF, Bergfeld WF: Finasteride in the treatment of alopecia. Expert Opin Pharmacother 2004;5:933-934.

18 Akhondzadeh S: Avicenna and evidence based medicine. Avicenna J Med Biotechnol 2014;6:1-2.

19 Feinstein AR: Clinical Judgement. Williams \& Wilkins, 1967.

20 Cochrane AL: Effectiveness and Efficiency: Random Reflections on Health Services, London: Nuffield Provincial Hospitals Trust, 1972.

21 Feinstein, Alvan R: The pre-therapeutic classification of co-morbidity in chronic disease. Journal of Chronic Diseases 1970;23:455468.

22 Mangin D, Heath I, Jamoulle M: Beyond diagnosis: rising to the multimorbidity challenge. BMJ 2012;344:e3526.

23 Jakovljević M, Ostojić L: Comorbidity and multimorbidity in medicine today: challenges and opportunities for bringing separated branches of medicine closer to each other. Psychiatr Danub 2013;25(suppl 1):18-28.
24 Yesudian P: Hail the dermato-trichologist! Int J Trichology 2014;6:85.

25 Yesudian P: Hair specialist, trichologist or dermato-trichologist? Int J Trichology 2010; 2:121.

26 Trüeb RM: Hair India 2012: A letter of Appreciation. Int J Trichology 2012;4:235.

27 Kaplan RM: Johann Christian Reil and the naming of our specialty. Australas Psychiatry 2012;20:157-158.

28 Nguyen T, Hong J, Prose NS: Compassionate care: enhancing physician-patient communication and education in dermatology. Part I: patient-centered communication. J Am Acad Dermatol 2013;68:353-360.

29 Hong J, Nguyen T, Prose NS: Compassionate care: enhancing physician-patient communication and education in dermatology. Part II: patient education. J Am Acad Dermatol 2013; 68:364-373.

30 Renzi C, Abeni D, Picardi A, et al: Factors associated with patient satisfaction with care among dermatological outpatients. Br J Dermatol 2001;145:617-623.

31 Kuntoji V, Kudligi C, Bhagwat PV, Asati DP, Bansal A: The tricky "trichs" in dermatology! Indian J Dermatol Venereol Leprol 2018;84: 109-113. 